\title{
A correlational study of suicidal ideation with psychological distress, depression, and demoralization in patients with cancer
}

\author{
Chun-Kai Fang • Ming-Chih Chang • Pei-Jan Chen • Ching-Chi Lin • Gon-Shen Chen • \\ Johnson Lin • Ruey-Kuen Hsieh • Yi-Fang Chang • Hong-Wen Chen • Chien-Liang Wu • \\ Kuan-Chia Lin $\cdot$ Yu-Jing Chiu $\cdot$ Yu-Chan Li
}

Received: 6 February 2013 / Accepted: 15 May 2014 /Published online: 17 June 2014

(C) The Author(s) 2014. This article is published with open access at Springerlink.com

\begin{abstract}
Purpose This study aims to study the effects of depression and demoralization on suicidal ideation and to determine the feasibility of the Distress Thermometer as a screening tool for patients with cancer who experience depression and demoralization, and thus to establish a model screening process for suicide prevention.
\end{abstract}

C.-K. Fang • Y.-J. Chiu

Department of Psychiatry and Suicide Prevention Center, Mackay

Memorial Hospital, Taipei, Taiwan

C.-K. Fang $\cdot$ Y.-F. Chang

Department of Medicine, Mackay Medical College, New Taipei City,

Taiwan

C.-K. Fang • Y.-C. Li

Department of Thanatology and Health Counseling, National Taipei University of Nursing and Health Sciences, Taipei, Taiwan

M.-C. Chang • G.-S. Chen · J. Lin · R.-K. Hsieh • Y.-F. Chang Division of Medical Oncology, Department of Internal Medicine, Mackay Memorial Hospital, Taipei, Taiwan

P.-J. Chen • C.-C. Lin • C.-L. Wu

Division of Pulmonary and Critical Care Medicine, Department of Internal Medicine, Mackay Memorial Hospital, Taipei, Taiwan

H.-W. Chen

Hospice and Palliative Care Center, Mackay Memorial Hospital,

Taipei, Taiwan

K.-C. Lin

Department of Health Care Management, National Taipei University of Nursing and Health Sciences, Taipei, Taiwan

Y.-C. Li $(\square)$

Institute of Life and Death Education and Counseling, National Taipei University of Nursing and Health Sciences, No.365, Mingde Rd., Beitou District, Taipei, Taiwan

e-mail: yuhchain@ntunhs.edu.tw
Methods Purposive sampling was used to invite inpatients and outpatients with lung cancer, leukemia, and lymphoma. Two hundred participants completed the questionnaire, which included the Distress Thermometer (DT), Patient Health Questionnaire-9 (PHQ-9), Demoralization Scale-Mandarin Version (DS-MV), and Beck Scale for Suicide Ideation. All data obtained were analyzed using SPSS 18.0 and SAS 9.3. Results Tobit regression analysis showed that demoralization influenced suicidal ideation more than depression $\operatorname{did}(t=2.84$, $p<0.01$ ). When PHQ- $9 \geq 10$ and DS-MV $\geq 42$ were used as criteria for the DT, receiver operating characteristic analysis revealed that the AUC values were $0.77-0.79$, with optimal cutoff points for both of DT $\geq 5$; sensitivity 76.9 and $80.6 \%$, respectively; and specificity of 73.9 and $72.2 \%$, respectively. Conclusions Demoralization had more influence on suicidal ideation than depression did. Therefore, attention should be paid to highly demoralized patients with cancer or high demoralization comorbid with depression for the purposes of suicide evaluation and prevention. The DT scale (with a cutoff of $\geq 5$ points) has discriminative ability as a screening tool for demoralization or depression and can also be used in clinical settings for the preliminary screening of patients with cancer and high suicide risk.

Keywords Demoralization syndrome $\cdot$ Depression · Distress thermometer $\cdot$ Suicide risk factor

\section{Introduction}

The risk of suicide is two to four times higher-and the standardized mortality ratio (SMR) of suicide is 1-11 times higher - in patients with cancer than in the general population [1-5]. The suicide mortality rate of patients with cancer reached 288.9/100,000/3 years in 2002-2004 in Taiwan [3], higher than those reached $31.4 / 100,000$ person-years in USA 
[4]. The standardized mortality ratio (SMR) of patients with cancer is approximately 6.7 higher than those in other countries: South East England (male SMR 1.4; women SMR 1.19) [6], Australian (SMR 1.78) [7], Korean (SMR 2) [8]. Indicating serious measures, suicide prevention among patients with cancer in Taiwan needs to be undertaken. Past studies have shown that suicide risk factors for patients with cancer include the length of time after preliminary diagnosis [9-13], gender $[10,14]$, type and stage of cancer $[3,9,11]$, psychological characteristics $[5,15]$, social support and economic resources $[4,12]$, lack of detection by clinical staff $[12,16,17]$, and so on. Among the assessed psychological factors involved in suicide risk, depression was regarded as the most important predictor $[16,18,19]$. Several studies have found that the Distress Thermometer (DT) [20-25], the Emotion Thermometer (ET) [26, 27], and the Brief Symptom Rating Scale (BSRS-5) [28] are highly accurate as a screening tool for depression. In Taiwan, only the DT was a valid measure for cancer patients [25]. BSRS-5 had not validated for cancer patients population. Thus, the DT can be used as a preliminary clinical screening tool for patients with cancer and depression to facilitate referral to further services and prevention of suicide risk factors.

Aside from the elevated incidence of depression in patients with cancer, there is also a higher incidence of demoralization syndrome; studies conducted in Australia [29], America [30], Ireland [31], Western Europe [32], Germany [33], Hungary [34], and Taiwan [35] have produced similar results. The concept of demoralization syndrome was proposed by Kissane and Clarke; it is experienced as a persistent inability to cope together with feelings of helplessness, hopelessness, and incompetence and the loss of aims and meaning in life [36]. However, some patients with cancer experience symptoms of demoralization without those of depression [29, 33, 35]. The diagnosis and treatment methods for demoralization differ from those for depression $[35,36]$. Both conditions can exist independently, but they can also be comorbid with each other [37]. Studies have shown that $14-27.4 \%$ of patients were demoralized but not depressed, while $21.7-33 \%$ experienced both demoralization and depression $[29,35]$.

From the clinical study point of view [36], demoralization is not necessarily related to psychiatric disorder; $29.5 \%$ of the patients were characterized by the absence of any DSM-IV comorbid disorder. What is more serious is that there is a statistically significant demoralization phenomenon among cancer patient in Taiwan [35]. If clinical diagnosis is limited to the DSM-IV diagnostic criteria for clinical depression or adjustment disorder, the abovementioned patients with cancer and severe demoralization will not be able to receive proper treatment; this could lead to a higher suicide risk for them $[38,39]$.

No previous research has investigated whether the presence of comorbid depression and demoralization affects suicidal ideation or whether the DT is suitable for the screening of patients with severe demoralization. Therefore, this study aims to investigate the relationships between psychological distress, depression, and demoralization on one hand with suicidal ideation on the other and to establish a model screening process for suicide prevention in patients with cancer.

\section{Methods}

\section{Design and participants}

The study was approved by the Mackay Memorial Hospital Committee of Human Testing and passed the inspection of the Institutional Review Board to allow clinical research (11MMHIS097). Because of limitations in labor and time, the study employed a questionnaire-based cross-sectional survey; data were collected from participants with lung cancer, leukemia, and lymphoma, including inpatients and outpatients, using purposive sampling. The exclusion criteria included uncertainty regarding cancer diagnosis, unwillingness to sign the participant consent form, inability to communicate effectively, the presence of cognitive impairment, psychotic illness, unable to understand written Chinese, unable to fill out four different questionnaires completely, and less than 20 years old.

Patients meeting these criteria were subsequently approached by the attending physician that gave consent to their patient' participation. Patients were invited to take part in the study and the study instruments were given by the research assistants. The research assistants were Master's candidates at the Institute of Counseling, and both had received $>2$ years of training in psychological counseling. Throughout the study, both research assistants were available to provide emotional support to the participants and refer them to psychooncology staff if needed. The period of data collection was between October 2011 and August 2012. In total, 209 participants filled out questionnaires, 200 participants filled out four questionnaires completely, and 9 participants filled out only some questionnaires. As mentioned above, six patients with cancer were unable to comprehend the questionnaire or refused to continue with the interview, and three were unable to complete four questionnaires for physiological reasons, leaving a total of 200 valid questionnaires.

\section{Measures}

\section{Beck scale for suicide ideation (BSI)}

The Beck Scale for Suicide Ideation (BSI) was developed as a self-reported measure according to Scale for Suicide Ideation [40]. This questionnaire was used to measure the participants' severity of suicidal ideation during the past week. The scoring range of each question was $0-2$ points (total range, 0-38 
points). There was no cutoff point for this measure; all scores above 0 indicated the presence of suicidal ideation. Higher scores indicate more severe suicidal ideation.

\section{Distress thermometer}

The DT is a self-report measure developed by the NCCN to detect psychological stress in patients with cancer [41]. It involves responding to a single question using a Likert scale in the form of a thermometer to indicate the psychological distress experienced within the past week ( 0 indicates no distress; 10 indicates extreme distress).

\section{Patient health questionnaire-9}

The Patient Health Questionnaire (PHQ-9) was developed as a self-reported measure [42]. Its nine questions assess the presence of the DSM-IV criteria for major depressive episodes across a 2-week period using responses on a four-point Likert scale. When the item scores are summed, a total score of $\geq 10$ corresponds to a diagnosis of major depressive disorder with sensitivity and specificity values of $88 \%$ [42]. In Taiwanese primary care settings, the PHQ-9 has satisfactory psychometric properties for the detection of major depressive disorder. The mean of Cronbach's $\alpha$ was 0.8 (95\% confidence interval [CI], 0.79-0.82), and the optimal cutoff score of PHQ- $9 \geq 10$ had $86 \%$ sensitivity and $93.9 \%$ specificity [43].

\section{Demoralization scale-mandarin version}

The Demoralization Scale-Mandarin Version (DS-MV) was translated from the demoralization scale developed by Kissane [29]. The DS-MV includes five distinct dimensions: loss of meaning (five items; $\alpha=0.84$ ), dysphoria (five items; $\alpha=0.69$ ), disheartenment (six items; $\alpha=0.88$ ), helplessness (four items; $\alpha=0.72$ ), and sense of failure (four items; $\alpha=0.63)$. The reliability and validity of the Mandarin version for patients with cancer has been revealed in our previous research (Cronbach's $\alpha=0.92$ ); thus, the DS-MV has acceptable psychometric properties when used in Taiwanese patients with cancer [44].

\section{Statistical analysis}

The statistical software packages SPSS 18.0 and SAS 9.3 were used for archiving and analysis. Independent-samples $t$ tests and ANOVAs were conducted to determine if there were significant differences in demographics and disease characteristics with respect to the different variables. With suicidal ideation as the dependent variable, the data set violated the assumption of the normality test $(p<0.001)$, having a rightskewed distribution. As the Tobit Model is suitable for testing non-normally distributed, left-skewed, right-skewed, or bilateral-intercepted data sets [45], the Tobit Model and Classification and Regression Tree (CART) were used to test the power of psychological distress, depression, and demoralization to predict suicidal ideation. The Sobel mediator test [46, 47] was also used to study the mediation effects of various psychological variables on suicidal ideation. Finally, receiver operating characteristic (ROC) [48] curves were computed to examine the ability of the DT to identify depression and demoralization. An ROC curve is a plot of a test's truepositive rate (sensitivity) over the false-positive rate (1-specificity) measured at each score cutoff value. The area under an ROC curve is a summary measure of the probability that a randomly drawn patient identified as a "case" will score higher on the test in question than a randomly draw patient who does not meet case criteria [49].

\section{Results}

Demographics and disease characteristics

Table 1 lists the demographics and disease characteristics of the 200 included patients.

Differences in suicidal ideation, psychological distress, depression, and demoralization on the bases of demographics

BSI score $\geq 1$ was regarded as indicating the presence of suicidal ideation (Table 1). A total of 59 patients $(29.5 \%)$ with cancer had BSI scores $\geq 1$ (mean BSI score, $3.88 \pm 4.04$ ). As shown in Table 1, there was one significant difference in suicidal ideation with respect to marital status $(F=3.08$, $p \leq 0.05$ ): unmarried participants had higher levels of suicidal ideation than married participants had. There were no significant differences in suicidal ideation between participants with other marital statuses.

The mean DT score was $3.46(\mathrm{SD}=2.48)$. A total 76 patients ( $36 \%$ ) scored $\geq 5$ points on the DT, which (according to NCCN standards [41]) implies that they have clinically apparent features of psychological distress. Patients with lung cancer had higher psychological distress than hematological patients $(t=2.56, p<0.05)$. There was one significant difference in psychological distress with respect to type of age $(F=3.92, p<0.05)$. Patients with $36-50$ years old had higher psychological distress compared to patients with 51-65 years old, and to patients with above 65 years old.

The mean PHQ-9 score was $6.06(\mathrm{SD}=4.30)$. In this study, 39 patients with cancer $(19.5 \%)$ scored $\geq 10$ points on the PHQ-9, implying that they may have fulfilled the diagnostic criteria for depression [43]. There were significant differences in levels of depression with respect to education level $(F=4.00, p<0.05)$, employment status $(t=-2.31, p<0.05)$, 
Table 1 Differential analysis of psychological distress, depression, and demoralization according to demographic variables

\begin{tabular}{|c|c|c|c|c|c|c|c|c|c|c|c|c|c|}
\hline \multirow[t]{2}{*}{$\begin{array}{l}\text { Demographic } \\
\text { variables }\end{array}$} & \multirow[t]{2}{*}{$\begin{array}{l}\text { Number of people } \\
(N=200)(\%)\end{array}$} & \multicolumn{3}{|c|}{$\begin{array}{l}\text { Suicidal ideation } \\
(N=200)\end{array}$} & \multicolumn{3}{|c|}{$\begin{array}{l}\text { Psychological } \\
\text { distress }(N=200)\end{array}$} & \multicolumn{3}{|l|}{$\begin{array}{l}\text { Depression } \\
(N=200)\end{array}$} & \multicolumn{3}{|l|}{$\begin{array}{l}\text { Demoralization } \\
(N=200)\end{array}$} \\
\hline & & $\begin{array}{l}\text { Mean } \\
\text { (SD) }\end{array}$ & $t$ & $F$ & $\begin{array}{l}\text { Mean } \\
\text { (SD) }\end{array}$ & $T$ & $F$ & $\begin{array}{l}\text { Mean } \\
\text { (SD) }\end{array}$ & $t$ & $F$ & Mean (SD) & $t$ & $F$ \\
\hline Gender & & & -0.85 & & & 0.15 & & & -1.57 & & & -0.99 & \\
\hline Female & $105(52.5 \%)$ & $0.98(2.23)$ & & & $3.49(2.55)$ & & & $5.61(4.02)$ & & & $27.37(13.60)$ & & \\
\hline Male & $95(47.5 \%)$ & $1.33(3.34)$ & & & $3.43(2.40)$ & & & $6.56(4.56)$ & & & $29.23(13.01)$ & & \\
\hline Age & & & & 0.93 & & & $3.92 *$ & & & 2.46 & & & 0.50 \\
\hline$\leq 35$ years & $24(12 \%)$ & $1.88(3.14)$ & & & $3.67(2.01)$ & & & $6.63(3.93)$ & & & $31.29(10.45)$ & & \\
\hline $36-50$ years & $56(28 \%)$ & $1.34(3.43)$ & & & $4.25(2.39)$ & & & $7.18(4.64)$ & & & $28.25(15.88)$ & & \\
\hline $51-65$ years & $111(55.5 \%)$ & $0.93(2.42)$ & & & $3.14(2.54)$ & & & $5.50(4.11)$ & & & $27.61(12.34)$ & & \\
\hline$>65$ years & $9(4.5 \%)$ & $0.67(2.00)$ & & & $1.89(2.03)$ & & & $4.56(4.13)$ & & & $28.11(15.41)$ & & \\
\hline Education & & & & 0.33 & & & 0.75 & & & $4.00 *$ & & & 2.40 \\
\hline Elementary school & $31(15.5 \%)$ & $0.81(2.87)$ & & & $3.26(2.76)$ & & & $4.26(3.65)$ & & & $29.39(13.15)$ & & \\
\hline Junior high school & $33(16.5 \%)$ & $1.39(3.80)$ & & & $3.88(3.08)$ & & & $8.18(5.03)$ & & & $34.18(14.14)$ & & \\
\hline Senior high school & $59(29.5 \%)$ & $1.15(2.09)$ & & & $3.25(2.66)$ & & & $5.88(4.05)$ & & & $25.92(13.65)$ & & \\
\hline College & $64(32 \%)$ & $1.28(3.02)$ & & & $3.67(2.33)$ & & & $6.28(4.17)$ & & & $27.31(12.07)$ & & \\
\hline Research institute & $13(6.5 \%)$ & $0.06(1.50)$ & & & $2.77(1.74)$ & & & $4.69(3.38)$ & & & $25.77(13.06)$ & & \\
\hline Marital status & & & & $3.08^{*}$ & & & 1.07 & & & 0.74 & & & 0.71 \\
\hline Never marred & $45(22.5 \%)$ & $2.02(3.92)$ & & & $3.71(2.37)$ & & & $6.53(3.73)$ & & & $30.76(10.16)$ & & \\
\hline Married & $131(65.5 \%)$ & $0.76(2.05)$ & & & $3.48(2.53)$ & & & $6.04(4.50)$ & & & $27.46(13.89)$ & & \\
\hline Divorced & $18(9 \%)$ & $2.00(4.04)$ & & & $3.22(2.34)$ & & & $5.78(1.12)$ & & & $27.50(15.60)$ & & \\
\hline Widowed & $6(3 \%)$ & $0.33(0.82)$ & & & $1.83(2.40)$ & & & $3.83(4.35)$ & & & $29.17(15.28)$ & & \\
\hline Employment status & & & -1.91 & & & -1.12 & & & & $-2.31^{*}$ & & & -1.90 \\
\hline Yes & $95(47.5 \%)$ & $0.76(2.06)$ & & & $3.25(2.50)$ & & & $5.33(3.77)$ & & & $26.39(13.15)$ & & \\
\hline No & $105(52.5 \%)$ & $1.50(3.32)$ & & & $3.65(2.46)$ & & & $6.71(4.65)$ & & & $29.94(13.30)$ & & \\
\hline Hospitalization & & & -0.48 & & & 1.58 & & & $-2.87 * *$ & & & $2.56^{*}$ & \\
\hline Outpatient & $132(46.5 \%)$ & $1.08(2.63)$ & & & $3.27(2.36)$ & & & $5.41(3.91)$ & & & $26.05(13.14)$ & & \\
\hline Inpatient & $68(53.5 \%)$ & $1.28(3.14)$ & & & $3.84(2.67)$ & & & $7.32(4.74)$ & & & $32.54(12.70)$ & & \\
\hline Type of malignancy & & & 0.98 & & & $2.56^{*}$ & & & $2.69 * *$ & & & $-3.35 * *$ & \\
\hline Lung & $93(66 \%)$ & $1.35(3.40)$ & & & $3.94(2.54)$ & & & $6.94(4.66)$ & & & $30.81(13.59)$ & & \\
\hline Hematological & $107(34 \%)$ & $0.96(2.17)$ & & & $3.05(2.36)$ & & & $5.30(3.81)$ & & & $26.04(12.74)$ & & \\
\hline Cancer stage & & & & 1.69 & & & 0.76 & & & 0.98 & & & 0.33 \\
\hline Stage I & $21(10.5 \%)$ & $2.48(4.59)$ & & & $3.52(2.33)$ & & & $6.48(4.03)$ & & & $26.95(12.80)$ & & \\
\hline Stage II & $27(13.5 \%)$ & $1.56(4.56)$ & & & $3.56(2.43)$ & & & $6.00(4.77)$ & & & $26.26(15.07)$ & & \\
\hline Stage III & $34(17 \%)$ & $0.97(2.17)$ & & & $3.91(2.38)$ & & & $6.88(4.15)$ & & & $29.24(13.81)$ & & \\
\hline Stage IV & $38(19 \%)$ & $0.76(1.76)$ & & & $3.68(2.40)$ & & & $6.55(4.28)$ & & & $29.53(12.82)$ & & \\
\hline Unknown & $80(40 \%)$ & $0.91(1.91)$ & & & $3.11(2.62)$ & & & $5.39(4.26)$ & & & $28.25(13.08)$ & & \\
\hline Time since diagnosis & & & & 0.66 & & & 0.11 & & & 0.29 & & & $2.86^{*}$ \\
\hline$<3$ months & $37(18.5 \%)$ & $1.03(3.62)$ & & & $3.57(2.59)$ & & & $6.35(4.51)$ & & & $28.35(11.44)$ & & \\
\hline 3 months- 1 year & $31(15.5 \%)$ & $0.68(1.30)$ & & & $3.32(2.21)$ & & & $6.26(5.22)$ & & & $26.00(11.19)$ & & \\
\hline $1-2$ years & $50(25 \%)$ & $1.02(2.33)$ & & & $3.58(2.59)$ & & & $6.28(4.15)$ & & & $32.76(13.01)$ & & \\
\hline$>2$ years & $82(41 \%)$ & $1.45(3.08)$ & & & $3.39(2.50)$ & & & $5.72(3.95)$ & & & $26.32(14.52)$ & & \\
\hline Treatment & & & -0.30 & & & 1.58 & & & 1.76 & & & $2.23 *$ & \\
\hline Continued & $141(70.5 \%)$ & $1.11(2.78)$ & & & $3.64(2.52)$ & & & $6.40(4.55)$ & & & $29.6(13.07)$ & & \\
\hline Discontinued & $59(29.5 \%)$ & $1.24(2.91)$ & & & $3.03(2.33)$ & & & $5.24(3.52)$ & & & $25.03(12.47)$ & & \\
\hline
\end{tabular}

$S D$ Standard Deviation, $t$ t statistics, $F F$ statistics

${ }^{*} p<0.05 ; * * p<0.01$

hospitalization status ( $t=-2.87, p<0.01)$, and type of malignancy $(t=-2.87, p<0.01)$. There were higher levels of depression in junior high school, unemployment, outpatient, and lung cancer patient group.
The mean DS-MV score over all participants was 28.26 $(\mathrm{SD}=13.32)$. In accordance with Kissane et al. [29], those scoring $\geq 30$ points ( 84 participants, $42 \%$ ) can be regarded as severely demoralized. An alternative suggested by Mullane 
et al. [31] was to categorize patients as demoralized according to the criterion of mean \pm 1 standard deviation; by that criterion, 31 participants $(15.5 \%)$ scoring $>42$ points (mean $+\mathrm{SD}=$ $28.26+13.32=41.58)$ could be categorized as highly demoralized. There were significant differences in level of demoralization with respect to current hospitalization status ( $t=-3.35, p<0.01)$, whether treatment was continued or discontinued ( $t=2.23, p<0.05)$, type of malignancy ( $t=2.56$, $p<0.05)$, and time since diagnosis $(F=2.86, p<0.05)$. There was higher demoralization in hospitalization status, continued treatment, lung cancer patients, and diagnosis during one to 2 years

Predictors and mediating factors influencing suicidal ideation

In summary, the results of the Tobit regression analysis (Table 2) show that marital status, psychological distress, and demoralization were effective predictors of suicidal ideation. Model 4 shows that, compared with psychological distress and depression, demoralization was a more significant predictor of suicidal ideation $(t=2.84, p<0.01)$. Model 5, in which the various subcomponents of demoralization are compared, shows that loss of meaning $(t=2.54, p<0.05)$ was a more significant predictor of suicidal ideation.

Results of the Sobel test (Table 3, Fig. 1) indicate that the effects of psychological distress on suicidal ideation were mediated by depression and demoralization, with mediating effect sizes of 50 and $77 \%$, respectively. This implies that patients with cancer who show signs of depression or demoralization and apparent psychological distress will experience an indirect increase in the magnitude of the effects of depression or demoralization on suicidal ideation by 50 and $77 \%$, respectively. On the other hand, when both depression and demoralization were set as mediating variables, the mediating effect size was $75.4 \%$, of which depression accounted for $18 \%$, demoralization $25 \%$, and depression $\times$ demoralization $31.8 \%$. Therefore, a depressed patient with cancer who experiences demoralization syndrome will experience an increased effect on suicidal ideation by 50-75.4\% above the effect of depression alone.

The results of CART analysis (Fig. 2) indicate that level of demoralization was the strongest predictor of suicidal ideation. The 47 participants who were categorized as highly demoralized had significantly higher levels of suicidal ideation (mean $=3.28, \mathrm{SD}=4.79$ ) than those with lower levels of demoralization $($ mean $=0.49, \mathrm{SD}=1.25$ ). Among highly demoralized participants, 24 had high demoralization comorbid with depression; those patients had significantly higher levels of suicidal ideation (mean $=4.25, \mathrm{SD}=6.11$ ) than the others $($ mean $=2.26, \mathrm{SD}=2.59)$.
Table 2 TOBIT analysis of various variables with respect to suicidal ideation

\begin{tabular}{|c|c|c|c|c|}
\hline Variable & $\beta$ & SE & $t$ & $p$ \\
\hline \multicolumn{5}{|l|}{ Model 1} \\
\hline Never married & 0.68 & 0.22 & $3.09 * *$ & 0.002 \\
\hline Divorced & 0.55 & 0.32 & 1.72 & 0.085 \\
\hline Widowed & -0.18 & 0.52 & -0.35 & 0.726 \\
\hline \multicolumn{5}{|l|}{ Married } \\
\hline \multicolumn{5}{|l|}{ Model 2} \\
\hline Never married & 0.65 & 0.21 & $3.04 * *$ & 0.002 \\
\hline Divorced & 0.57 & 0.31 & 1.85 & 0.065 \\
\hline Widowed & -0.02 & 0.51 & -0.03 & 0.977 \\
\hline Distress & 0.10 & 0.04 & $2.85^{* *}$ & 0.004 \\
\hline \multicolumn{5}{|l|}{ Model 3} \\
\hline Never married & 0.64 & 0.21 & $2.99 * *$ & 0.003 \\
\hline Divorced & 0.58 & 0.31 & 1.88 & 0.060 \\
\hline Widowed & 0.02 & 0.51 & 0.04 & 0.966 \\
\hline Distress & 0.06 & 0.04 & 1.63 & 0.104 \\
\hline Depression & 0.04 & 0.02 & 1.91 & 0.056 \\
\hline \multicolumn{5}{|l|}{ Model 4} \\
\hline Never married & 0.58 & 0.21 & $2.78 * *$ & 0.005 \\
\hline Divorced & 0.56 & 0.30 & 1.85 & 0.064 \\
\hline Widowed & -0.13 & 0.50 & -0.26 & 0.792 \\
\hline Distress & 0.04 & 0.04 & 1.04 & 0.300 \\
\hline Depression & 0.01 & 0.03 & 0.38 & 0.701 \\
\hline Demoralization & 0.02 & 0.01 & $2.84 * *$ & 0.005 \\
\hline \multicolumn{5}{|l|}{ Model 5} \\
\hline Never married & 0.57 & 0.21 & $2.69 * *$ & 0.007 \\
\hline Divorced & 0.60 & 0.30 & $2.02 *$ & 0.043 \\
\hline Widowed & -0.16 & 0.50 & -0.31 & 0.753 \\
\hline Distress & 0.04 & 0.04 & 0.93 & 0.352 \\
\hline Depression & -0.01 & 0.05 & -0.22 & 0.824 \\
\hline Loss of meaning & 0.10 & 0.04 & $2.54^{*}$ & 0.011 \\
\hline Dysphoria & 0.07 & 0.04 & 1.91 & 0.057 \\
\hline Disheartenment & 0.01 & 0.04 & 0.33 & 0.740 \\
\hline Helplessness & -0.08 & 0.05 & -1.67 & 0.095 \\
\hline Sense of failure & -0.03 & 0.04 & -0.71 & 0.481 \\
\hline
\end{tabular}

$\beta$ Standardized coefficients, $S E$ standard error, $t$ tobit statistics

$* p<0.05 ; * * p<0.01$

Detecting psychological distress using DT, depression, and demoralization

When using PHQ-9 $\geq 10$ as the criterion for depression, the AUC value for the DT scale was 0.79 . The acceptable range of AUC values is .5-1; higher AUC values indicate higher scale accuracy, and the largest value on Youden's index determines the optimal cutoff point [48]. The results indicate that the DT scale has acceptable discriminative ability as a screening tool for depression, with an optimal cutoff of 5 points, sensitivity of $76.9 \%$, and specificity of $73.9 \%$. Using the demoralization criterion of DS-MV $\geq 30$ as a reference point, the AUC value of the DT scale was 0.67 , with an optimal cutoff of 5 points, 
Table 3 Mediation analysis of depression and demoralization on psychological distress leading to suicidal ideation

M1 $18.1 \%$, M2 $25.4 \%, M 1 \times M 2$ $31.9 \%$

\begin{tabular}{lllll}
\hline Mediating variables & B-Crude & B-Adjusted & $\begin{array}{l}\text { Indirect effects (\%) } \\
\left(c-c^{\prime} / c\right)\end{array}$ & $\begin{array}{l}\text { Direction of } \\
\text { confounding effect }\end{array}$ \\
\hline Depression & 0.214 & 0.107 & $50 \%$ & + \\
Demoralization & 0.214 & 0.076 & $77 \%$ & + \\
$\begin{array}{l}\text { Depression (M1) and } \\
\text { demoralization (M2) }\end{array}$ & 0.214 & 0.514 & $75.4 \%$ & + \\
\hline
\end{tabular}

sensitivity of $54.8 \%$, and specificity of $77.6 \%$. Using DS$\mathrm{MV} \geq 42$ as a reference point, the AUC value for the DT scale was 0.77 , with an optimal cutoff of 5 points, sensitivity of $80.6 \%$, and specificity of $72.2 \%$.

Thus, it can be seen that the DT (with a cutoff of 5 points) is suitable for the preliminary screening of patients with depression or high levels of demoralization, but was not distinguish in the severity of demoralization or depression.

\section{Discussion}

Comparisons of suicidal ideation, psychological distress, depression, and demoralization with the results of other studies

The results of this study reveal significant differences in suicidal ideation with respect to marital status: unmarried individuals had higher levels of suicidal ideation than married

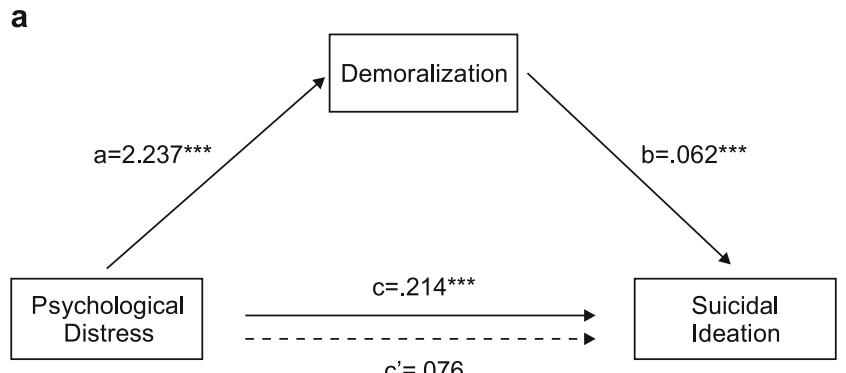

$c^{\prime}=.076$

b

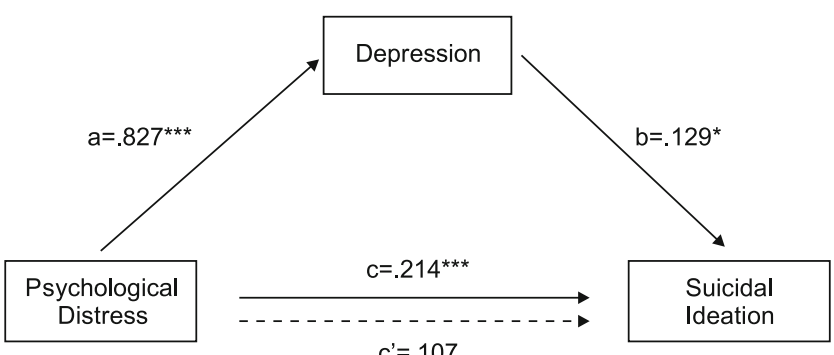

Fig. 1 a Depression used as mediating variable; $\mathbf{b}$ demoralization used as mediating variable. Note: ${ }^{*} p<0.05,{ }^{* * *} p<0.001$ patients did. This finding is similar to previous ones, whereby married persons had lower suicide rates than unmarried ones [50]. Marriage is an important source of social support (including material and emotional support) that reduces suicidal ideation [51].

With regard to psychological distress, $36 \%$ of patients in this study fulfilled the referral criteria for psychological distress. This is similar to the results of previous studies, whereby $35.1-37.8 \%$ of patients with cancer experienced apparent psychological distress [52, 53]. Moreover, the results of this study showed that patients with lung cancer had higher levels of psychological distress than those with hematological malignancies, while patients aged 3650 years had higher levels of psychological distress than those aged $51-65$ or $>65$ years. These are similar to past findings that associated different malignancies [24, 51, 52] and younger age with higher levels of psychological distress [22, 54].

The results of this study showed that patients with lung cancer, inpatients, and unemployed patients had higher levels of depression than those who had hematological malignancies, were inpatients, and were currently employed. These results are similar to those of previous studies [55-58]. Not only can employment provide economic support to patients with cancer but it is also an important source of emotional support $[59,60]$ and a way for patients to create social roles, as it as an opportunity to connect with others and society, thus improving self-identity [61]. Patients with cancer who stopped working because of the disease or treatment might have lost sources of self-identity and emotional support; this in turn might have increased the risk associated with depression.

The patients' mean demoralization score was $28.26 \pm$ 13.32, with $42 \%$ of patients assigned as highly demoralized (DS-MV $\geq 30$ ). This result is similar to the findings of Kissane et al. [29] in Australia and Mehnert et al. [33] in Germany, who found mean demoralization scores of $30.82 \pm 17.73$ and $29.8 \pm 10.41$, respectively. According to various criteria, 39.1-47\% of patients with cancer were highly demoralized. Patients with lung cancer, inpatients, and patients currently receiving treatment had higher levels of demoralization than patients with hematological malignancies, outpatients, and patients who had discontinued treatment. 
Fig. 2 CART analysis to predict suicidal ideation
BSI

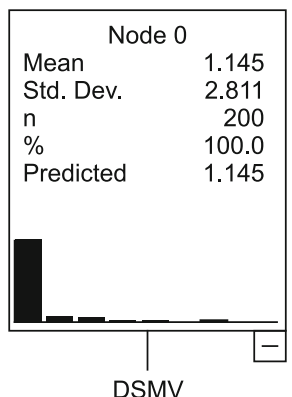

Improvement $=1.396$

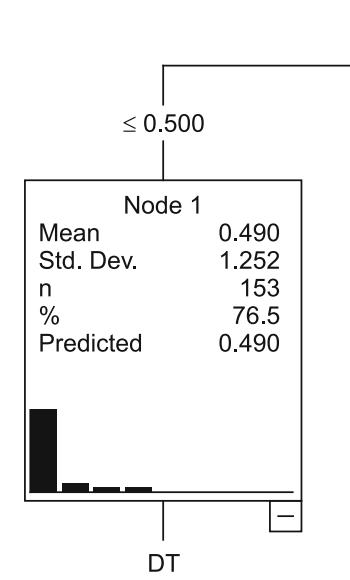

Improvement $=0.036$

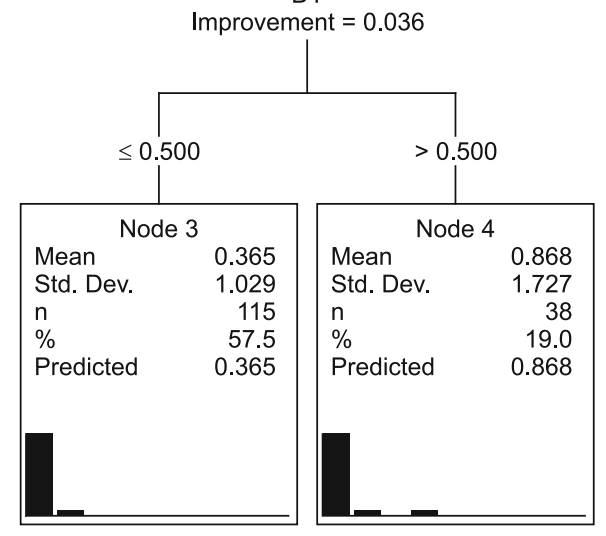

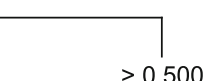

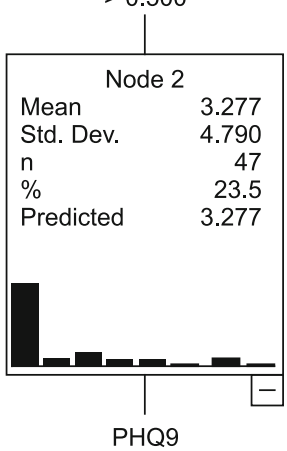

Improvement $=0.232$

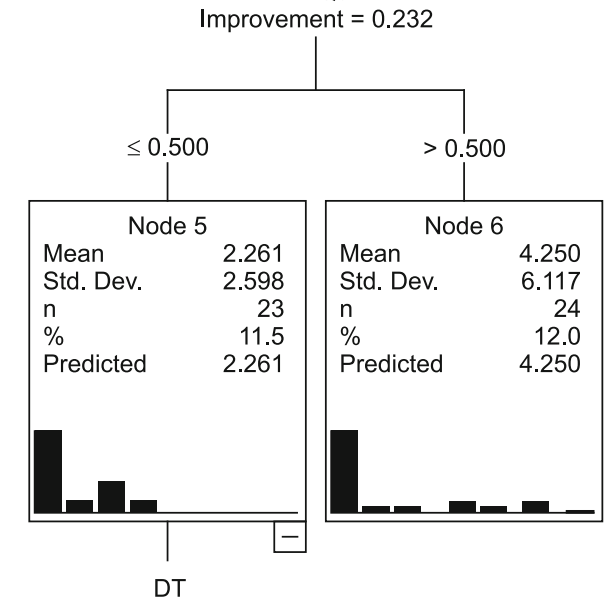

Improvement $=0.021$

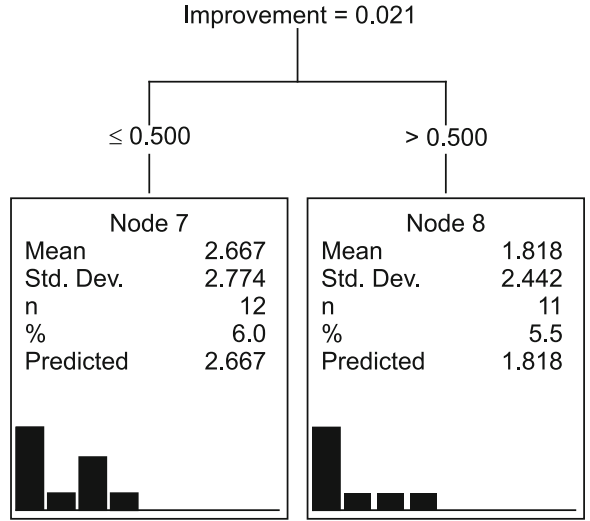

These are similar to the results of previous studies, which showed that different types of malignancies and continuation vs. discontinuation of treatment resulted in different levels of demoralization [35]. 


\section{Predictors of suicidal ideation}

Compared with previous studies, which found that depression was an important predictor of suicidal ideation $[16,18,19]$, this study's Tobit and CART analyses revealed that demoralization had higher predictive power for suicidal ideation; further, patients experiencing demoralization comorbid with depression had even higher levels of suicidal ideation. The results of Sobel analysis were in line with the abovementioned results, as demoralization can mediate between depression and suicidal ideation. For patients with cancer and depressive tendencies, the presence of demoralization increases the effect of depression on suicidal ideation by $50-75.4 \%$. This result is similar to the viewpoint proposed by Rickelman [62], which suggests that the relationship between depression and demoralization is a continuous, depressogenic response. The only deviating point made in this study is that Rickelman used attributional arguments to propose that demoralization is a precursor of depression; thus, when demoralization recurs persistently or its severity increases, it will develop into depression. In order to address these discrepancies in theory and results, further studies can be conducted on highly demoralized and highly depressed patients with cancer using a longitudinal follow-up method to investigate the development of the relationship between demoralization and depression.

Furthermore, this study found that loss of meaning was an important factor in the effect of demoralization on suicidal ideation. This result is similar to that of previous studies that showed that the loss of meaning subscale and the Schedule for Attitudes toward Hastened Death (SAHD) were highly correlated. This supports the hypothesis proposed by Kissane et al. that demoralization independently predicts the desire for hastened death [29]. Current research has shown that improved coping strategies that involve meaning-making in patients with cancer can help them to adapt to their situation; these can also be an important protective factor against depression or demoralization [63-65] while reducing suicidal ideation and improving spiritual well-being [66]. This section highlights the importance of meaningfulness in the reduction of suicidal ideation in patients with cancer.

\section{Optimal cutoff points in DT with respect to PHQ-9 and DS-MV}

The results reveal that the AUC value of the DT for detecting depression was 0.79 , which is an acceptable level of discriminative ability. This result is similar to that of Hegel et al. [23], who studied patients with preliminary diagnoses of breast cancer; their administration of the DT gave an AUC value of 0.87 . The only difference was that the previous study generated an optimal cutoff point of 7 points, which differs from the cutoff of 5 points found in this study. Whereas that study measured the length of time since preliminary diagnosis of breast cancer and the decision to resect the tumor, this study included patients who had had cancer for an average of 35 months, with patients who had had cancer for $>2$ years accounting for a significant proportion of the group (41\%). The results of Ozalp et al. [21] indicated that newly diagnosed patients with cancer had higher levels of psychological distress than the ones diagnosed the previous year; thus, our study estimated that time after diagnosis is an important factor influencing the cutoff point of DT.

In addition, the results of this study show that the criteria of DS-MV $\geq 30$ or 42 points have acceptable levels of discriminative ability with respect to demoralization; DS-MV $\geq 42$ was the most accurate reference point. This was in line with the procedure of Mullane et al. [31], whereby mean $\pm \mathrm{SD}$ was used to categorize demoralization levels; this contrasts with the method proposed by Kissane et al. [29], whereby the median (30) was used as a cutoff for categorization; the present method gives better discriminative ability.

The BSI was developed by Beck in West country; thus, it may be necessary to account for cultural differences in attitudes regarding life and death. Unlike the views of the original authors, whereby accepting one's fate or not actively avoiding death when one's life is threatened is seen as passive and suicidal, the results of this study indicated that most patients accepted the inevitability of death due to illness; this follows from the fact that allowing nature to take its course is part of the Taoist/Confucian cultural viewpoint. This reflects the influence of cultural differences on attitudes toward life and death, which result in differing views on the definition of passive suicidal intent. Therefore, the scale might have misrepresented the severity of suicidal ideation in Taiwanese patients with cancer; this problem cannot be completely ruled out.

In summary, aside from the significant relationship between depression and suicidal ideation that was revealed in past studies, demoralization is also an important risk factor that influences suicidal ideation in patients with cancer. The present results highlight that highly demoralized patients have higher suicide risks and require further attention for the purpose of suicide prevention. The results indicate that the optimal cutoff point for the DT is $\geq 5$ points and that it has good discriminative ability as a screening tool. Therefore, the DT (with a cutoff of 5 points) can be used in clinical settings for the preliminary screening of patients with cancer comorbid with depression or high levels of demoralization, tagging them as patients with high suicide risk. The DS-MV and PHQ-9 can then be used to determine the severity of demoralization or depression, thus allowing for the provision of different treatments or referral models in order to provide a complete screening process for suicide prevention in patients with cancer. 
Acknowledgments We appreciate all doctors and research assistants who helped in this study, including Dr. Yu-Jen Chen, Dr. Chih-Kung Lin, Dr. Huan-Chao Lin, Dr. Nai-Wen Su, Dr. Jian Su, Dr. Kou-Hwa Chang, Dr. Chang-Yi Lin, Dr. Yu-Chung Kung, Dr. Ming-Jen Peng, Dr. WenChien Huang, Mr. Pei-Chen Yeh, and Ms. Shih-Hsuan Pi.

Conflict of interest The research received no specific funding. There are no conflicts of interest to declare. Chun-Kai Fang (first author) and Yu-Chan Li (corresponding author) have full control of all primary data.

Open Access This article is distributed under the terms of the Creative Commons Attribution Noncommercial License which permits any noncommercial use, distribution, and reproduction in any medium, provided the original author(s) and the source are credited.

\section{References}

1. Hem E, Loge JH, Haldorsen T, Ekeberg O (2004) Suicide risk in patients with cancer from 1960 to 1999. J Clin Oncol 22: 4209-4216

2. Mann JJ, Apter A, Bertolote J, Beautrais A, Currier D, Haas A, Hegerl U, Lonnqvist J, Malone K, Marusic A, Mehlum L, Patton G, Phillips M, Rutz W, Rihmer Z, Schmidtke A, Shaffer D, Silverman M, Takahashi Y, Varnik A, Wasserman D, Yip P, Hendin H (2005) Suicide prevention strategies - a systematic review. JAMA 294:2064-2074

3. Misono S, Weiss NS, Fann JR, Redman M, Yueh B (2008) Incidence of suicide in persons with cancer. J Clin Oncol 26:4731-4738

4. Chung KH, Lin HC (2010) Methods of suicide among patients with cancer - a nationwide population-based study. Suicide Life Threat Behav 40:107-114

5. Robson A, Scrutton F, Wilkinson L, MacLeod F (2010) The risk of suicide in patients with cancer: a review of the literature. Psychooncology 19:1250-1258

6. MacFarlane E, Benke G, Del Monaco A, Sim MR (2009) Cancer incidence and mortality in a historical cohort of Australian pest control workers. Occup Environ Med 66:818-823

7. Robinson D, Renshaw C, Okello C, Moller H, Davies EA (2009) Suicide in cancer patients in South East England from 1996 to 2005: a population-based study. Br J Cancer 101:198-201

8. Ahn E, Shin DW, Cho SI, Park S, Won YJ, Yun YH (2010) Suicide rates and risk factors among Korean cancer patients1993-2005. Cancer Epidemiol Biomarkers Prev 19:2097-2105

9. Miccinesi G, Crocetti E, Benvenuti A, Paci E (2004) Suicide mortality is decreasing among patients with cancer in Central Italy. Eur J Cancer 40:1053-1057

10. Yousaf U, Christensen ML, Engholm G, Storm HH (2005) Suicides among Danish patients with cancer 1971-1999. Br J Cancer 92:995-1000

11. Dormer N, McCaul K, Kristjanson L (2008) Risk of suicide in patients with cancer in Western Australia 1981-2002. Med J Aust 188:140-143

12. Lin $\mathrm{HC}, \mathrm{Wu} \mathrm{CH}$, Lee HC (2009) Risk factors for suicide following hospital discharge among patients with cancer. Psychooncology 18: 1038-1044

13. Johnson TV, Garlow SJ, Brawley OW, Master VA (2012) Peak window of suicides occurs within the first month of diagnosis: implications for clinical oncology. Psychooncology 21:351-356

14. Akechi T, Okamura H, Nakano T, Akizuki N, Okamura M, Shimizu K, Okuyama T, Furukawa TA, Uchitomi Y (2010) Gender differences in factors associated with suicidal ideation in major depression among patients with cancer. Psychooncology 19:384-389
15. Rasic DT, Belik SL, Bolton JM, Chochinov HM, Sareen J (2008) Cancer, mental disorders, suicidal ideation and attempts in a large community sample. Psychooncology 17:660-667

16. Akechi T, Nakano T, Akizuki N, Nakanishi T, Yoshikawa E, Okamura H, Uchitomi Y (2002) Clinical factors associated with suicidality in patients with cancer. Jpn J Clin Oncol 32:506-511

17. Valente SM (2010) Oncology nurses' knowledge of suicide evaluation and prevention. Cancer Nurs 33:290-295

18. Breitbart W, Rosenfeld B, Pessin H, Kaim M, Funesti-Esch J, Galietta M, Nelson CJ, Brescia R (2000) Depression, hopelessness, and desire for hastened death in terminally ill patients with cancer. JAMA 284:2907-2911

19. Akechi T, Okamura H, Nishiwaki Y, Uchitomi Y (2002) Predictive factors for suicidal ideation in patients with unresectable lung carcinoma. Cancer 95:1085-1093

20. Ransom S, Jacobsen PB, Booth-Jones M (2006) Validation of the Distress Thermometer with bone marrow transplant patients. Psychooncology 15:604-612

21. Ozalp E, Cankurtaran ES, Soygur H, Geyik PO, Jacobsen PB (2007) Screening for psychological distress in Turkish patients with cancer. Psychooncology 16:304-311

22. Gessler S, Low J, Daniells E, Williams R, Brough V, Tookman A, Jones L (2008) Screening for distress in patients with cancer: is the distress thermometer a valid measure in the UK and does it measure change over time? A prospective validation study. Psychooncology 17:538-547

23. Hegel MT, Collins ED, Kearing S, Gillock KL, Moore CP, Ahles TA (2008) Sensitivity and specificity of the Distress Thermometer for depression in newly diagnosed breast patients with cancer. Psychooncology 17:556-560

24. Shim EJ, Shin YW, Jeon HJ, Hahm BJ (2008) Distress and its correlates in Korean patients with cancer: pilot use of the distress thermometer and the problem list. Psychooncology 17:548-555

25. Wang GL, Hsu SH, Feng AC, Chiu CY, Shen JF, Lin YJ, Cheng CC (2011) The HADS and the DT for screening psychosocial distress of patients with cancer in Taiwan. Psychooncology 20: 639-646

26. Mitchell A (2010) Can the Distress Thermometer be improved by additional mood domains? Part I. Initial validation of the Emotion Thermometers tool. Psycho-Oncology 19:125-133

27. Mitchell AJ, Baker-Glenn EA, Park B, Granger L, Symonds P (2010) Can the distress thermometer be improved by additional mood domains? Part II. What is the optimal combination of emotion thermometers? Psycho-Oncology 19:134-140

28. Chen HC, Wu CH, Lee YJ, Liao SC, Lee MB (2005) Validity of the five-item brief symptom rating scale among subjects admitted for general health screening. J Formos Med Assoc 104:824-829

29. Kissane DW, Wein S, Love A, Lee XQ, Kee PL, Clarke DM (2004) The Demoralization Scale: a report of its development and preliminary validation. J Palliat Care 20:269-276

30. Cockram CA, Doros G, de Figueiredo JM (2009) Diagnosis and measurement of subjective incompetence: the clinical hallmark of demoralization. Psychother Psychosom 78:342-345

31. Mullane M, Dooley B, Tiernan E, Bates U (2009) Validation of the Demoralization Scale in an Irish advanced cancer sample. Palliat Support Care 7:323-330

32. Grassi L, Sabato S, Rossi E, Biancosino B, Marmai L (2005) Use of the diagnostic criteria for psychosomatic research in oncology. Psychother Psychosom 74:100-107

33. Mehnert A, Vehling S, Hocker A, Lehmann C, Koch U (2011) Demoralization and depression in patients with advanced cancer: validation of the German version of the Demoralization Scale. J Pain Symptom Manag 42:768-776

34. Hadnagy Z, Csikos A, Nagy L (2012) Introduction of the demoralization scale in Hungary, a study on demoralization and depression among hospice patients. Orv Hetil 153:737-743 
35. Lee CY, Fang CK, Yang YC, Liu CL, Leu YS, Wang TE, Chang YF, Hsieh RK, Chen YJ, Tsai LY, Liu SI, Chen HW (2012) Demoralization syndrome among cancer outpatients in Taiwan. Support Care Cancer 20:2259-2267

36. Rafanelli C, Guidi J, Gostoli S, Tomba E, Porcelli P, Grandi S (2013) Subtyping demoralization in the medically ill by cluster analysis. Eur J Psychiatry 27:7-17

37. Shader RI (2005) Demoralization revisited. J Clin Psychopharmacol 25:291-292

38. Clarke DM, Kissane DW (2002) Demoralization: its phenomenology and importance. Aust N Z J Psychiatry 36:733-742

39. Strada EA (2009) Grief, demoralization, and depression-diagnostic challenges and treatment modalities. Prim Psychiatry 16:49-55

40. Beck AT, Steer RA, Ranieri WF (1988) Scale for suicide ideation: psychometric properties of a self-report version. J Clin Psychol 44: 499-505

41. Holland JC, Jacobsen PB, Riba MB (2001) NCCN distress management. Cancer Control 8:88-93

42. Kroenke K, Spitzer RL, Williams JBW (2001) The PHQ-9: validity of a brief depression severity measure. J Gen Intern Med 16:606-613

43. Liu SI, Yen ZT, Huang HC, Sun FJ, Tjung JJ, Hwang LC, Shih YH, Yeh AW (2011) Validation of Patient Health Questionnaire for depression screening among primary care patients in Taiwan. Compr Psychiatry 52:96-101

44. Hung HC, Chen HW, Chang YF, Yang YC, Liu CL, Hsieh RK, Leu YS, Chen YJ, Wang TE, Tsai LY, Liu SI, Fang CK (2010) Evaluation of the reliability and validity of the Mandarin Version of Demoralization Scale for cancer patients. J Intern Med Taiwan 21: 427-435 (in Chinese)

45. Lin KC, Cheng SF (2011) Tobit model for outcome variable is limited by censoring in nursing research. Nurs Res 60:354-360

46. Baron RM, Kenny DA (1986) The moderator-mediator variable distinction in social psychological research: conceptual, strategic, and statistical considerations. J Pers Soc Psychol 51: $1173-1182$

47. Preacher KJ, Hayes AF (2004) SPSS and SAS procedures for estimating indirect effects in simple mediation models. Behav Res Methods Instrum Comput 36:717-731

48. Akobeng AK (2007) Understanding diagnostic tests 3: receiver operating characteristic curves. Acta Paediatr 96:644-647

49. Zweig MH, Capmbell G (1993) Receiver operating characteristic(ROC) plots: a fundamental evaluate on tool in clinical medicine. Clin Chem 39:561-577

50. Schneider KL, Shenassa E (2008) Correlates of suicide ideation in a population-based sample of patients with cancer. J Psychosoc Oncol 26:49-62

51. Heikkinen M, Aro H, Lonnqvist J (1993) Life events and social support in suicide. Suicide Life Threat Behav 23:343-358
52. Zabora J, BrintzenhofeSzoc K, Curbow B, Hooker C, Piantadosi S (2001) The prevalence of psychological distress by cancer site. Psychooncology 10:19-28

53. Carlson LE, Angen M, Cullum J, Goodey E, Koopmans J, Lamont L, MacRae JH, Martin M, Pelletier G, Robinson J, Simpson JS, Speca M, Tillotson L, Bultz BD (2004) High levels of untreated distress and fatigue in patients with cancer. Br J Cancer 90:2297-2304

54. Graves KD, Arnold SM, Love CL, Kirsh KL, Moore PG, Passik SD (2007) Distress screening in a multidisciplinary lung cancer clinic: prevalence and predictors of clinically significant distress. Lung Cancer 55:215-224

55. McDaniel JS, Musselman DL (1995) Depression in patients with cancer: diagnosis, biology, and treatment. Arch Gen Psychiatry 52:89-99

56. McDonough E, Boyd J, Varvares M, Maves MD (1996) Relationship between psychological status and compliance in a sample of patients treated for cancer of the head and neck. Head Neck 1:269-276

57. Massie MJ (2004) Prevalence of depression in patients with cancer. Natl Cancer Inst Monogr 32:57-71

58. Reisine S, Morse D, Psoter W, Eisenberg E, Cohen D, Cleveland D, Mohit-Tabatabai M (2005) Sociodemographic risk indicators for depressive symptoms among persons with oral cancer or oral epithelial dysplasia. J Oral Maxillofac Surg 63:513-520

59. Main DS, Nowels CT, Cavender TA, Etschmaier M, Steiner JF (2005) A qualitative study of work and work return in cancer survivors. Psychooncology 14:992-1004

60. Kennedy F, Haslam C, Munir F, Pryce J (2007) Returning to work following cancer: a qualitative exploratory study into the experience of returning to work following cancer. Eur J Cancer Care 16:17-25

61. Rasmussen DM, Elverdam B (2008) The meaning of work and working life after cancer: an interview study. Psychooncology 17: 1232-1238

62. Rickelman BL (2002) Demoralization as a precursor to serious depression. J Am Psychiatry Nurses Assoc 8:9-17

63. Holland JC, Reznik I (2005) Pathways for psychosocial care of cancer survivors. Cancer 104:2624-2637

64. Lee V (2008) The existential plight of cancer: meaning making as a concrete approach to the intangible search for meaning. Support Care Cancer 16:779-785

65. Vehling S, Lehmann C, Oechsle K, Bokemeyer C, Krull A, Koch U, Mehnert A (2011) Global meaning and meaning-related life attitudes: exploring their role in predicting depression, anxiety, and demoralization in patients with cancer. Support Care Cancer 19: $513-520$

66. Breitbart W, Rosenfeld B, Gibson C, Pessin H, Poppito S, Nelson C, Tomarken A, Timm AK, Berg A, Jacobson C, Sorger B, Abbey J, Olden M (2010) Meaning-centered group psychotherapy for patients with advanced cancer: a pilot randomized controlled trial. Psychooncology 19:21-28 